\title{
BMJ Open Caregiver burden versus intensity of anxiety and depression symptoms in parents of children with cerebral palsy as well as factors potentially differentiating the level of burden: a cross-sectional study (Poland)
}

\author{
Barbara Gugała
}

To cite: Gugała B. Caregiver burden versus intensity of anxiety and depression symptoms in parents of children with cerebral palsy as well as factors potentially differentiating the level of burden: a cross-sectional study (Poland). BMJ Open 2021;11:e036494. doi:10.1136/ bmjopen-2019-036494

- Prepublication history for this paper is available online. To view these files, please visit the journal online (http://dx.doi. org/10.1136/bmjopen-2019036494).

Received 19 December 2019 Revised 23 March 2021 Accepted 26 March 2021
Check for updates

(C) Author(s) (or their employer(s)) 2021. Re-use permitted under CC BY-NC. No commercial re-use. See rights and permissions. Published by BMJ.

Medical College, University of Rzeszów, Rzeszow, Poland

Correspondence to Dr Barbara Gugała; bgugala@ur.edu.pl

\section{ABSTRACT}

Objectives To assess the relationship between caregiver burden and severity of symptoms of anxiety/depression in parents of children with cerebral palsy (CP), and to identify factors differentiating the level of caregiver burden.

Setting Regional rehabilitation centres in South-Eastern Poland.

Participants The study involved 190 parents of children with $\mathrm{CP}$, that is, 138 women and 52 men.

Primary and secondary outcome measures Caregiver burden was assessed using Caregiver Burden Scale (CBS), while the intensity of anxiety and depression symptoms was measured using Hospital Anxiety and Depression Scale (HADS). Potential predictors were examined using Gross Motor Function Classification System for Cerebral Palsy (GMFCS), Barthel Index (BI) as well as a questionnaire focusing on the characteristics of the child, the parent and the family. The analyses applied Pearson's linear correlation coefficient as well as multiple regression analysis.

Results All the CBS measures are significantly correlated to HADS-A (anxiety) and HADS-D (depression). Intensity of anxiety is most visibly linked to CBS measures of disappointment and environment $(p<0.0001)$, while severity of depression is related to emotional involvement and general strain $(p<0.0001)$. The factors differentiating caregiver burden measure in the subscales of general strain $(p<0.0001)$ and social isolation $(p<0.0001)$ include the child's age and $\mathrm{BI}$, and the parent's health status; in the subscale of disappointment $(p<0.0001)$ - the child's age, BI, GMFCS, as well as the parent's age and health status; in the subscale of emotional involvement $(\mathrm{p}=0.0007)-\mathrm{Bl}$, and the parent's health status; in the subscale of environment $(p=0.0002)$ - the child's age and Bl.

Conclusions There is a positive linear relationship between the caregiver burden measures and severity of anxiety and depression. Effort should be made to relieve caregiver burden in parents of children with $\mathrm{CP}$.
Strengths and limitations of this study

- The methodology applied, involving the use of standardised survey questionnaires, makes it possible to compare the current findings with results reported by other researchers worldwide.

- Exploratory nature of the assessment.

- The study involved a small group of subjects.

- The subjects were only recruited in the regions of South-Eastern Poland.

\section{INTRODUCTION}

Cerebral palsy (CP), due to the numerous neurological, sensory and behavioural deficits, is linked with significant limitations in the overall functioning not only of the child but also his/her closest family, and poses a great challenge for the primary parental caregivers who are essential in ensuring balanced development of the child. ${ }^{1} \mathrm{CP}$ is a chronic condition defined as a group of functional limitations resulting from abnormalities in the development of the central nervous system (CNS). The clinical picture of CP, which generally is greatly varied, at a later stage of the child's growth is determined by the level of development and maturity of the CNS at the time the adverse factors were in operation. ${ }^{2}$ Motor disability is manifested by such phenomena as paretic limbs, involuntary movements, as well as poor balance and motor coordination. The symptoms first appear during early childhood, and they persist throughout the patient's life. In addition to these motor defects, there are numerous sensory and communication-related problems, as well as secondary musculoskeletal disorders. ${ }^{3}{ }^{4}$ The level of support required in order to satisfy the child's biopsychosocial 
needs depends on the level of disability, as well as limitations in the child's activity and performance in daily functioning. While taking care of a child with $\mathrm{CP}$, the parent must, in the daily life, cope with the child's motor and sensory disabilities, and implement a wide range of necessary medical and rehabilitation interventions. The main challenges faced by primary parental caregivers include management of the child's health problems in compliance with standard care requirements. The burden of care significantly exceeds normal requirements associated with stages of the child's development. ${ }^{5}$ Long-term care of a child with CP, linked with a need to handle the related problems and adversities, generates a significant caregiver burden for the primary parent, leading to difficulties in maintaining emotional balance and frequently becoming one of the most arduous life experiences. Such excessive care-related responsibilities may adversely affect the parents' physical and mental health, as well as their social, cultural and professional life. ${ }^{6-13}$ In the literature excessive caregiver burden is presented as a multidimensional problem, or a combination of objective and subjective characteristics. These include physical issues-mainly linked with the affected child's functional condition; mental aspects-connected with the parent's ability to cope with a stressful situation of managing a child with a disorder; social problems-reflected in the parent's relations with other people and financial difficulties-linked to the parent's discontinued employment, as well as costs of the child's treatment and rehabilitation. Subjective burden is related to experiences, feelings and attitudes linked to provision of care. ${ }^{14-16}$ Hence, caregiver burden is a result of a dynamic interaction between care demands related to the person in need of assistance, and the situation of caring as well as the caregiver's resources and sensitivity. Most published studies focusing on caregiver burden have investigated the problem in relation to geriatric populations and patients with mental diseases, cancer and neurological disorders. ${ }^{17-20}$ Research assessing problems of caring for children with chronic conditions mainly takes into account isolated medical conditions such as asthma, diabetes, cancer and mucoviscoidosis. ${ }^{21}$

In all the cases researchers report caregiver burden and suggest possible association of subjective burden with impairments to mental and physical health. Assessments have also focused on dependent and independent predictors of caregiver burden. All the related studies emphasise the multidimensional aspects of caregiver burden, its causes and consequences. ${ }^{14}$ 22-24 Conversely, caregiver burden in parents of children with $\mathrm{CP}$ has not been investigated extensively. To the best of my knowledge, this is the first study in Poland assessing the relationship between caregiver burden in parents of children with CP and subjectively perceived mental health problems, and additionally designed to identify independent contributing factors. The study aimed to:

1. Assess the relationship between caregiver burden and intensity of anxiety and depression symptoms in parents of children with CP.
2. Identify child and parent related factors differentiating the level of caregiver burden.

\section{MATERIALS AND METHODS}

\section{Patient and public involvement}

No patients or public were involved in setting the research question or the outcome measures, nor were they involved in the design and implementation of the study. There are no plans to involve patients in dissemination.

\section{Settings and participants}

The present article reports partial findings of a more comprehensive cross-sectional controlled study conducted in a population of primary parental caregivers of children with CP and a group of parents of healthy children. Due to the specificity of the Caregiver Burden Scale (CBS) as a research tool, caregiver burden was not assessed in the parents of healthy children. ${ }^{12}$

The study involved 190 parents of children with CP, that is, 138 women and 52 men, and was conducted from May 2013 to June 2016. The participants were recruited among families of children receiving specialist services in regional rehabilitation centres. The researcher made personal contact with all the eligible parents in the relevant facilities and obtained informed consent in writing from those who agreed to take part in the survey. The questionnaires were completed by the respondents without any assistance, in the facilities providing support for the children.

\section{Eligibility to participate in the study}

The following inclusion criteria were applied in the recruitment process, regarding the children: CP diagnosed in accordance with International Statistical Classification of Diseases and Related Health Problems (ICD)-10, and age from 2 to 18 years, and regarding the parents: self-reported status of the child's primary parent (based on the hours of care provided), permanent residence with the child, no financial compensation for the care, no mental illness diagnosed and no antidepressant treatment, as well as a written consent to participate in the study. The sociodemographic characteristics of the families, the parents and their children were identified using a specially designed questionnaire.

A total of 242 subjects took part in the recruitment procedure, however, 40 individuals were not qualified because they did not meet the inclusion criteria specified for parents of children with CP (25 individuals were not the primary parents, 3 individuals were receiving antidepressant treatment, 13 individuals did not sign the informed consent form). After the questionnaires were collected, 12 were rejected due to missing sociometric data and other incomplete responses. It was assumed that correctly completed surveys were those in which responses were given to all the questions. Ultimately, the study group consisted of 190 parents who met all the inclusion criteria and provided informed consent to participate in the study. All the subjects participating in the study were 
Table 1 Sociodemographic and family characteristics

\begin{tabular}{|c|c|c|}
\hline \multicolumn{2}{|l|}{ Variable } & Mean \pm SD (range) \\
\hline \multicolumn{2}{|c|}{ Age of caregiver (years) } & $40.6 \pm 9.1(22-69)$ \\
\hline & & N (\%) \\
\hline \multirow[t]{2}{*}{ Sex of caregiver } & Female & $138(72.6)$ \\
\hline & Male & $52(27.4)$ \\
\hline \multirow[t]{2}{*}{ Place of residence } & Rural area & $115(60.5)$ \\
\hline & Urban area & 75 (39.5) \\
\hline \multirow[t]{3}{*}{ Education } & Vocational & $70(36.8)$ \\
\hline & Secondary & $74(38.9)$ \\
\hline & Higher & $46(24.2)$ \\
\hline \multirow{3}{*}{$\begin{array}{l}\text { Occupational status } \\
\text { of caregiver }\end{array}$} & Both parents work & $43(22.8)$ \\
\hline & $\begin{array}{l}\text { One of the parents } \\
\text { works }\end{array}$ & $133(70.4)$ \\
\hline & $\begin{array}{l}\text { Neither of the parents } \\
\text { works }\end{array}$ & $13(6.8)$ \\
\hline \multirow[t]{3}{*}{ Economic security } & Good & $27(6.9)$ \\
\hline & Mediocre & 69 (36.3) \\
\hline & Poor & 94 (49.5) \\
\hline \multirow[t]{2}{*}{ Type of family } & Complete & $165(86.8)$ \\
\hline & Incomplete & $25(13.2)$ \\
\hline \multirow[t]{3}{*}{ Religiosity } & Practicing Catholic & $153(80.5)$ \\
\hline & $\begin{array}{l}\text { Non-practising } \\
\text { Catholic }\end{array}$ & $32(16.8)$ \\
\hline & Non-believers & $5(2.7)$ \\
\hline \multirow{5}{*}{$\begin{array}{l}\text { Satisfaction with } \\
\text { own health status }\end{array}$} & Very satisfied & $20(10.5)$ \\
\hline & Satisfied & $80(42.1)$ \\
\hline & $\begin{array}{l}\text { Neither satisfied nor } \\
\text { dissatisfied }\end{array}$ & $66(34.7)$ \\
\hline & Dissatisfied & $24(12.6)$ \\
\hline & Very dissatisfied & $0(0.0)$ \\
\hline \multirow[t]{2}{*}{ Living conditions } & A house & $130(68.4)$ \\
\hline & Block of flats & $60(31.6)$ \\
\hline \multirow{2}{*}{$\begin{array}{l}\text { Separate room for } \\
\text { a child }\end{array}$} & Yes & $101(53.2)$ \\
\hline & No & $89(46.8)$ \\
\hline \multirow{4}{*}{$\begin{array}{l}\text { The number of } \\
\text { people taking care } \\
\text { of the child }\end{array}$} & One & $46(24.2)$ \\
\hline & Two & $111(58.4)$ \\
\hline & Three & $26(13.7)$ \\
\hline & Four & $7(3.7)$ \\
\hline \multirow{4}{*}{$\begin{array}{l}\text { The number of } \\
\text { children in the } \\
\text { family }\end{array}$} & One & 37 (19.5) \\
\hline & Two & 67 (35.3) \\
\hline & Three & $58(30.5)$ \\
\hline & More than three & $28(14.7)$ \\
\hline
\end{tabular}

biological parents of the children. The response indexes in the study group amounted to 78.5\%. The subjects' mean age was 40.6 years. Detailed sociodemographic characteristics of the study group are presented in the Results section (table 1).

The questionnaires were handed to the participants on paper, and they needed from 15 to $30 \mathrm{~min}$ to fill in the survey during their visit in hospital. The completed surveys and the consent documents were kept separately to ensure the subjects' anonymity. The parents who were willing to participate in the study were informed about its main purpose, the importance of their input, confidentiality of and issues addressed by the surveys, as well as the time needed for completing the survey. ${ }^{25}$

\section{Clinical parameters}

The data related to the children of the parents in the study group, such as the diagnosis of CP type and assessment of motor capacities based on Gross Motor Function Classification System for Cerebral Palsy (GMFCS), were retrieved from the patients' records kept at the hospital ward.

\section{Measures \\ Measuring tools applied.}

\section{Specially designed questionnaire}

Specially designed questionnaire assessed sociodemographic characteristics of the primary parents, their families and children. The data related to the children were retrieved from the patients' records kept at the hospital ward. The assessment of the economic status took into account the previous year (12 months). The subject was asked to select one of the three responses describing the family's economic security as: good, if they had enough money for basic needs, for the child' rehabilitation and to save; mediocre, if the available resources were sufficient for essentials but not for saving; and poor, if the family's resources were insufficient for essentials. Satisfaction with one's health status was assessed on a 5-point Likert scale, with the score of 5 corresponding to 'very satisfied' and 1 to 'very unsatisfied'.

\section{Caregiver Burden Scale}

The questionnaire is designed as a tool enabling assessment of objective and subjective burden of care; it comprises 22 questions organised in five subscales: general strain (8 questions), social isolation (3 questions), disappointment (5 questions), emotional involvement (3 questions) and environment (3 questions) covering aspects of care related to physical functioning of the child with CP in and out of home. The responses were given on a 4-point rating scale. Overall burden was reflected by the mean score in all the subscales. Greater score corresponded to higher burden. The scores in the subscales were in the range from 1 to 4 . In line with other authors, the following burden categories were defined: low (score of 1.00-1.99), medium (score of 2.00-2.99) and high (score of 3.00-4.00). The coefficient of internal consistency expressed by Cronbach's alpha for the Polish version of the scale is $0.90 .{ }^{26}$

\section{Hospital Anxiety and Depression Scale}

The questionnaire is a screening tool enabling assessment of anxiety and depression symptoms in various medical conditions and in the general population. It comprises 
14 questions constituting two 'hidden' subscales for anxiety and depression (7 questions each). The responses are rated on a 4-point scale from 0 to 3 points, with the theoretical scores in each subscale ranging from 0 to 21 points. A score of more than 10 points indicates an anxiety disorder or depression. The value of Cronbach's alpha coefficient for the whole anxiety and depression subscale in the Polish version of the tool amounts to $0.81-0.89 .^{27}$

\section{Barthel Index}

A modified 20-point scale, is commonly used in assessing functional independence in 10 activities of daily living, that is, feeding, bed to chair transfers, grooming, toilet use and bathing, mobility on level surfaces and stair climbing, dressing, bladder control, and bowel control. Five rating categories were applied: total dependency, severe, moderate, slight dependency and lack of dependency. ${ }^{28}$

\section{Gross Motor Function Classification System for Cerebral Palsy}

GMFCS is used to assess progress in development of the motor function in children with $\mathrm{CP}$, relative to their age and severity of the disorder. The evaluation system comprises five levels (from I to $\mathrm{V}$ ) in four age groups, that is, below 2 years; 2-4 years; $4-6$ years; $6-12$ years and $12-18$ years of age. Particular emphasis is placed on evaluating the functions of sitting, walking and wheeled mobility. At each rating level and for each age category the motor abilities and independence in performing the activities are specified in detail. The general recommendations for assessment at each level are as follows: level I-ability to walk without limitations, level II-ability to walk with limitations, level III—ability to walk using assistive devices (supports), level IV-limited independent mobility, use of powered wheelchair, level V-wheelchair mobility facilitated by other people. ${ }^{29}$ For the needs of the analyses, the children representing various levels of motor function development were divided into two groups. These reflected the level of independent mobility in the children with CP. The first group comprised children at motor level I-III, that is, able to walk on their own with or without assistive mobility devices. The second group consisted of children with level IV-V motor abilities, that is, incapable of independent mobility. This distinction is relevant to caregiver burden assessment.

\section{Data analysis}

Arithmetic means, medians, SD and percentage fractions were applied in the statistical description. The analysis was conducted taking into account the numerical values reflecting the measures of CBS and Hospital Anxiety and Depression Scale (HADS). The effects of selected factors in the measures of CBS were examined using Pearson's linear correlation coefficient as well as multiple regression analysis. A procedure of forward stepwise regression was applied to determine an optimum regression model. Statistically significant improvement of the fit, reflected by the significant change $(\mathrm{p}<0.05)$ of coefficient of determination $\left(R^{2}\right)$, was the criterion for variable inclusion in

\begin{tabular}{|c|c|c|c|}
\hline CBS measures & Mean $(95 \% \mathrm{Cl})$ & Median & SD \\
\hline General strain & 2.59 (2.51 to 2.67 ) & 2.50 & 0.58 \\
\hline Isolation & 2.48 (2.39 to 2.58 ) & 2.50 & 0.67 \\
\hline Disappointment & 2.50 (2.42 to 2.59$)$ & 2.40 & 0.59 \\
\hline $\begin{array}{l}\text { Emotional } \\
\text { involvement }\end{array}$ & 2.67 (2.57 to 2.77 ) & 2.67 & 0.71 \\
\hline Environment & 2.49 (2.39 to 2.59$)$ & 2.33 & 0.73 \\
\hline Overall burden & 2.55 (2.47 to 2.63 ) & 2.57 & 0.55 \\
\hline
\end{tabular}

CBS, Caregiver Burden Scale.

the stepwise regression model. Also, Student's t-test for independent samples was used to assess significance of differences between the groups. Statistical significance was assumed for the values of $\mathrm{p}<0.05$.

\section{RESULTS}

\section{Sociodemographic characteristics of parents}

Majority of primary parental caregivers of the children with CP were women, residents of rural areas, and individuals reporting poor economic security. The largest groups included individuals with secondary education, representing complete families, with two or three children and one working parent (table 1).

\section{Measures of caregiver burden and their relationship with self- reported anxiety and depression}

The parents of the children with CP reported moderate level of caregiver burden. The highest level of burden was observed in the category of emotional involvement (table 2).

The effects of caregiver burden in the intensity of anxiety and depression symptoms are shown by the values of linear correlation coefficients and their statistical significance. All the measures of caregiver burden (CBS) have been shown to correlate significantly with HADS-A (anxiety) and HADS-D (depression). Higher burden appears to correspond to greater level of anxiety and depression (table 3).

Further analyses were designed to assess the association between subjective caregiver burden and intensity of anxiety and depression symptoms. For this purpose, combined relations of all the measures of CBS and HADS-A as well as HADS-D were examined using regression analysis. The regression models applied specific measures of CBS as independent variables, while HADS-A and HADS-D measures were used as dependent variables. An optional analysis took into account sociodemographic and other factors (listed in table 1), which were additionally included in the model. Some of these were present in the models describing the level of depression or anxiety, but they did not change the relationship between the measures of CBS and HADS. Due to this the author decided to present here the simplified forms 
Table 3 Linear correlations between CBS and HADS measures

\begin{tabular}{|c|c|c|}
\hline \multirow{2}{*}{$\begin{array}{l}\text { Measures of } \\
\text { caregiver burden } \\
\text { (CBS) }\end{array}$} & \multicolumn{2}{|l|}{ HADS } \\
\hline & $\begin{array}{l}\text { HADS-A } \\
\text { (anxiety) }\end{array}$ & $\begin{array}{l}\text { HADS-D } \\
\text { (depression) }\end{array}$ \\
\hline General strain & $0.53(p<0.0001)$ & $0.37(p<0.0001)$ \\
\hline Isolation & $0.38(p<0.0001)$ & $0.29(p<0.0001)$ \\
\hline Disappointment & $0.51(p<0.0001)$ & $0.37(p<0.0001)$ \\
\hline $\begin{array}{l}\text { Emotional } \\
\text { involvement }\end{array}$ & $0.28(p=0.0001)$ & $0.16(p=0.0232)$ \\
\hline Environment & $0.48(p<0.0001)$ & $0.41(p<0.0001)$ \\
\hline Overall burden & $0.51(p<0.0001)$ & $0.38(p<0.0001)$ \\
\hline
\end{tabular}

CBS, Caregiver Burden Scale; HADS, Hospital Anxiety and Depression Scale.

of models, without taking into account the sociodemographic factors.

An optimum regression model was selected using forward stepwise regression procedure. The model describing the measure of anxiety (HADS-A) was found to comprise two CBS measures-disappointment and environment. The model explains approximately $30 \%$ of the HADS-A related variability in the study group. Both the entire model and the two factors comprised therein were found to be statistically significant. The value of the standardised regression coefficient $B$ shows slightly greater effect of the measure of disappointment in HADS-A (table 4).

Modelling of the numerical measure of depression (HADS-D) by means of CBS measures allowed to explain only $18.8 \%$ of the variability in depression intensity in the relevant population. The model comprised two CBS measures, that is, general strain and environment ( $p$ value for general strain was slightly above 0.05 , but this factor was finally included in model because it improved model fit significantly). A stronger association was observed between environment and HADS-D (table 5).

Presentation of measures linked to the condition of the child in the study group

The data related to the children with $\mathrm{CP}$ are shown in table 6 .

Table 4 Regression model describing the relationship of HADS-A and Caregiver Burden Scale measures

\begin{tabular}{|c|c|c|c|}
\hline \multirow{3}{*}{$\begin{array}{l}\text { Independent } \\
\text { variables }\end{array}$} & \multicolumn{3}{|l|}{ HADS-A (anxiety) } \\
\hline & $R^{2}=29.3 \%$ & $F=38.7$ & $p<0.0001$ \\
\hline & B (95\% Cl) & $\beta$ & P value \\
\hline Disappointment & $1.979(1.034$ to 2.924$)$ & 0.341 & $<0.0001$ \\
\hline Environment & $1.186(0.413$ to 1.959$)$ & 0.250 & 0.0028 \\
\hline
\end{tabular}

HADS, Hospital Anxiety and Depression Scale.
Table 5 Regression model describing the relationship of HADS-D and Caregiver Burden Scale measures (the model was identified through forward stepwise regression)

\begin{tabular}{|c|c|c|c|}
\hline \multirow{3}{*}{$\begin{array}{l}\text { Independent } \\
\text { variables }\end{array}$} & \multicolumn{3}{|l|}{ HADS-D (depression) } \\
\hline & $R^{2}=18.8 \%$ & $F=21.6$ & $p<0.0001$ \\
\hline & B (95\% Cl) & $\boldsymbol{\beta}$ & $P$ value \\
\hline General strain & $1.131(-0.023$ to 2.285$)$ & 0.173 & 0.0547 \\
\hline Environment & 1.540 (0.622 to 2.459$)$ & 0.296 & 0.0011 \\
\hline
\end{tabular}

HADS, Hospital Anxiety and Depression Scale.

\section{Analysis of the effects of independent factors in CBS measures}

Assessment of the subjective caregiver burden in the parents of children with CP, controlled for independent factors, was carried out by means of regression analysis. The measures determined using CBS questionnaire (general strain, isolation, disappointment, emotional involvement, environment, overall burden) were applied in the regression models as the dependent variables, while the initial set of independent variables was based on the data from tables 1 and 6 . A procedure of forward stepwise regression was applied to select factors producing statistically significant effects in the CBS measures. Ultimately the analysis took into account the following characteristics related to the children: sex, age, functional efficiency determined by Barthel Index (BI), as well as GMFCS level (dichotomous distinction of groups: IV-V vs I-III); and characteristics associated with the parent and the family: the

\begin{tabular}{lllc}
\hline \multicolumn{3}{l}{ Table 6} & \multicolumn{3}{l}{ Characteristics of the children with CP } \\
\hline Variable & & Mean (SD) & Range \\
\hline Age of children in years & $11.0(4.3)$ & $2-16$ \\
Sex & Male & 120 & $\%$ \\
& Female & 70 & 63.2 \\
CP type & Spastic diplegia & 98 & 36.8 \\
& Spastic hemiplegia & 43 & 51.6 \\
& Spastic quadriplegia & 26 & 13.6 \\
& Other & 23 & 12.1 \\
GMFCS & I & 25 & 13.2 \\
level & II & 48 & 25.3 \\
& III & 35 & 18.4 \\
& IV & 44 & 23.2 \\
& V & 38 & 20.0 \\
Barthel & Very severe & 54 & 28.4 \\
Index & Severe & 57 & 30.0 \\
& Moderate & 30 & 15.8 \\
& Mild & 49 & 25.8
\end{tabular}

CP, cerebral palsy; GMFCS, Gross Motor Function Classification System for Cerebral Palsy. 
Table 7 Characteristics of CBS measures in the entire group with respect to the children's motor capacities (GMFCS level)

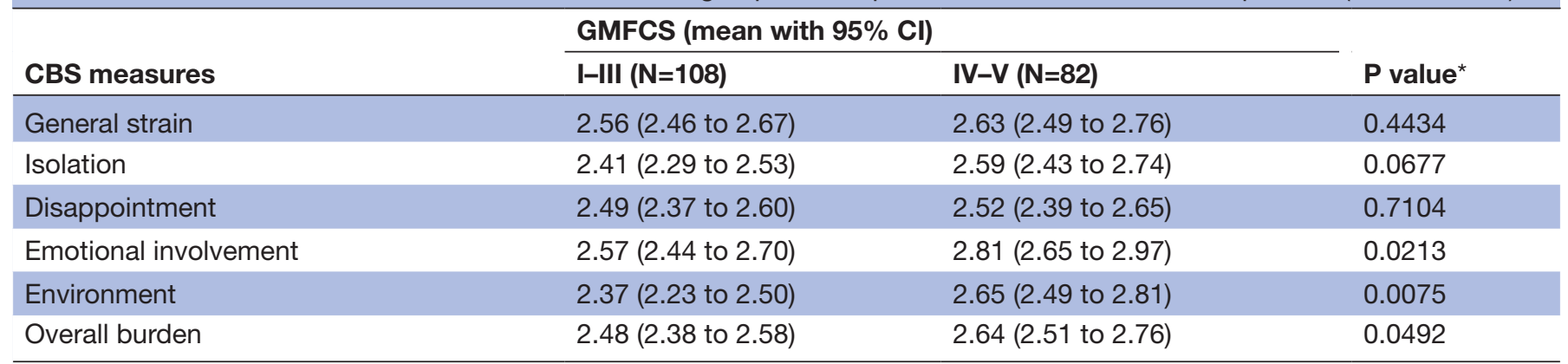

${ }^{*} \mathrm{P}$ value for test probability calculated using t-test for independent samples.

CBS, Caregiver Burden Scale; GMFCS, Gross Motor Function Classification System for Cerebral Palsy.

parent's age and sex, place of residence (rural vs urban area), education (vocational/secondary vs higher), the primary parent's health status, parents' occupational status (one parent vs both parents working), economic security (poor vs good) and number of children in the family. To facilitate the interpretation, the demographic factors were shown in dichotomous forms.

\section{Characteristics of the CBS measures with respect to the children's} GMFCS level

A comparison of the measures of burden with respect to the children's motor capacities assessed with GMFCS showed that care of children with higher GMFCS scores tends to be more burdensome-which is particularly reflected in the dimensions of environment and emotional involvement, and in the synthetic measure of overall burden (table 7 ).

\section{Regression model for predicting CBS measures}

A procedure of forward stepwise regression was applied to select factors producing statistically significant effects, separately for each CBS measure as a dependent variable. The results of regression analysis are shown only for the factors which were found to be statistically significant. Obviously, CBS measures are correlated, however, the relationships are not strong enough to justify anticipation of identical results of regression analysis for each of them (the values of correlation coefficients for the component CBS measures most frequently are not higher than 0.7 , which corresponds to determination coefficient below $50 \%$ ). The following model explains $14.9 \%$ of the variability in general strain. The measure of general strain was shown to be significantly affected by the child's age, the child's BI score and the parent's health status. Older age of the child seems to correspond to higher burden, and a 1-point increase in BI coincides with a decrease in general strain by 0.019 . The measure of general strain is 0.290 point higher in parents with mediocre health status compared with the parents with good health status. The findings are shown in table 8 .

The model explains $10.4 \%$ of total variability in the measure of social isolation. The measure increases with the child's age (on average by 0.026 per year); a 1-point increase in $\mathrm{BI}$ coincides with a decrease in the measure of social isolation by 0.020 , while the parent's mediocre health status is associated with a measure of social isolation which on average is 0.254 point higher (table 9 ).

The model describing effects produced by independent factors in the measure of disappointment comprised five variables, which jointly explained $13.8 \%$ of the variability in this measure. The effects of the child's age, BI and the parent's health status were similar to those observed in the previous models, however, the findings show that the level of disappointment is lower with respect to care of a child with a higher level of motor disability (on average it is 0.309 point lower in the case of GMFCS levels of IV-V). The measure of disappointment is 0.259 point higher in the parents reporting mediocre health status compared with those with good health status. The older parents tend to be less disappointed than the younger ones, the effect of this factor approaches statistical significance $(\mathrm{p}=0.0536$, that is only slightly higher than 0.05 ) (table 10).

The factors which significantly affect the measure of emotional involvement include the level of functional efficiency according to BI, and the parents' health status. The joint effect of these factors is not very high-they explain only $7.5 \%$ of the variability in the measure of emotional involvement. Nevertheless, these two factors differentiate the level of burden in the category of emotion. The nature of these effects is similar to those

Table 8 Regression model for predicting Caregiver Burden Scale-general strain

\begin{tabular}{|c|c|c|c|}
\hline \multirow{3}{*}{$\begin{array}{l}\text { Independent } \\
\text { variables }\end{array}$} & \multicolumn{3}{|l|}{ General strain } \\
\hline & $R^{2}=14.9 \%$ & $F=10.9$ & $p<0.0001$ \\
\hline & B (95\% Cl) & $\beta$ & $P$ value \\
\hline $\begin{array}{l}\text { Age of children } \\
\text { (years) }\end{array}$ & $\begin{array}{l}0.026(0.008 \text { to } \\
0.045)\end{array}$ & 0.197 & 0.0056 \\
\hline Barthel Index & $\begin{array}{l}-0.019(-0.031 \text { to } \\
-0.006)\end{array}$ & -0.200 & 0.0038 \\
\hline $\begin{array}{l}\text { Health status } \\
\text { (worse vs better) }\end{array}$ & $\begin{array}{l}0.290(0.131 \text { to } \\
0.450)\end{array}$ & 0.251 & 0.0004 \\
\hline
\end{tabular}


Table 9 Regression model for predicting Caregiver Burden Scale-social isolation

\begin{tabular}{|c|c|c|c|}
\hline \multirow{3}{*}{$\begin{array}{l}\text { Independent } \\
\text { variables }\end{array}$} & \multicolumn{3}{|l|}{ Social isolation } \\
\hline & $R^{2}=10.4 \%$ & $F=7.2$ & $p<0.0001$ \\
\hline & B (95\% Cl) & $\boldsymbol{\beta}$ & $P$ value \\
\hline $\begin{array}{l}\text { Age of children } \\
\text { (years) }\end{array}$ & $\begin{array}{l}0.026(0.004 \text { to } \\
0.048)\end{array}$ & 0.169 & 0.0198 \\
\hline Barthel Index & $\begin{array}{l}-0.020(-0.035 \text { to } \\
-0.006)\end{array}$ & -0.190 & 0.0074 \\
\hline $\begin{array}{l}\text { Health status } \\
\text { (worse vs better) }\end{array}$ & $\begin{array}{l}0.254 \text { (0.066 to } \\
0.442)\end{array}$ & 0.191 & 0.0084 \\
\hline
\end{tabular}

in the previous models: a 1-point increase in BI on average coincides with a decrease by 0.027 in the relevant measure, and the parents with mediocre health status perceive greater emotional burden, which on average is 0.224 point higher (table 11 ).

The factors producing statistically significant effect in the measure of burden related to environment include the child's age and their functional efficiency assessed with BI. The factor of age is negatively correlated to the measure of environment, that is, functioning of the child in and out of home, which means that caregiver burden increases with the child's age. It is also logical that caregiver burden decreases with higher value of BI (greater functional efficiency) (table 12).

Forward stepwise regression made it possible to identify a model comprising factors which produced significant effects in the measure of overall burden. This model explains approximately $13 \%$ of the variability in overall burden. The factors significantly affecting overall burden include: the child's age (the older the child the greater the burden), BI (the lower the child's efficiency the greater the burden) and the parent's health status-caregiver

Table 10 Regression model for predicting Caregiver Burden Scale-disappointment

\begin{tabular}{|c|c|c|c|}
\hline \multirow{3}{*}{$\begin{array}{l}\text { Independent } \\
\text { variables }\end{array}$} & \multicolumn{3}{|l|}{ Disappointment } \\
\hline & $R^{2}=13.8 \%$ & $F=5.9$ & $p<0.0001$ \\
\hline & B (95\% Cl) & $\beta$ & $P$ value \\
\hline $\begin{array}{l}\text { Age of children } \\
\text { (years) }\end{array}$ & $\begin{array}{l}0.029(0.007 \text { to } \\
0.052)\end{array}$ & 0.211 & 0.0114 \\
\hline Barthel Index & $\begin{array}{l}-0.036(-0.055 \text { to } \\
-0.017)\end{array}$ & -0.377 & 0.0002 \\
\hline $\begin{array}{l}\text { GMFCS (IV-V } \\
\text { vs I-III) }\end{array}$ & $\begin{array}{l}-0.309(-0.548 \text { to } \\
-0.070)\end{array}$ & -0.258 & 0.0116 \\
\hline $\begin{array}{l}\text { Age of parent } \\
\text { (years) }\end{array}$ & $\begin{array}{l}-0.011(-0.021 \text { to } \\
0.000)\end{array}$ & -0.160 & 0.0536 \\
\hline $\begin{array}{l}\text { Health status } \\
\text { (worse vs } \\
\text { better) }\end{array}$ & $\begin{array}{l}0.259(0.091 \text { to } \\
0.427)\end{array}$ & 0.218 & 0.0028 \\
\hline
\end{tabular}

GMFCS, Gross Motor Function Classification System for Cerebral Palsy.
Table 11 Regression model for predicting Caregiver Burden Scale-emotional involvement

\begin{tabular}{|c|c|c|c|}
\hline \multirow{3}{*}{$\begin{array}{l}\text { Independent } \\
\text { variables }\end{array}$} & \multicolumn{3}{|c|}{ Emotional involvement } \\
\hline & $R^{2}=7.5 \%$ & $F=7.6$ & $p=0.0007$ \\
\hline & B (95\% Cl) & $\boldsymbol{\beta}$ & $P$ value \\
\hline Barthel Index & $\begin{array}{l}-0.027(-0.043 \text { to } \\
-0.011)\end{array}$ & -0.236 & 0.0010 \\
\hline $\begin{array}{l}\text { Health status } \\
\text { (worse vs } \\
\text { better) }\end{array}$ & $\begin{array}{l}0.224(0.028 \text { to } \\
0.421)\end{array}$ & 0.159 & 0.0257 \\
\hline
\end{tabular}

burden on average is approximately 0.230 point greater in individuals with poorer health compared with those reporting good health (table 13 ).

\section{DISCUSSION}

The study was conducted in order to assess the level of caregiver burden in relation to intensity of anxiety and depression symptoms in parents of children with CP and to identify predictors of overall caregiver burden. Analysis of the findings suggests that the level of emotional problems in a parent is not only a predictor of the burden but may also be seen as a visible consequence of care-related duties. Analysis of the independent variables affecting measures of burden showed that the causes of burden are of multifactorial nature. The presented regression models explain from $7.5 \%$ to approximately $15 \%$ of the variability in the measures of burden. The key predictors of caregiver burden include the child's age, motor capacity and functional status, and the parent's health status and age. While comparing the present findings with those reported by other authors it was found that few cross-sectional studies published so far had focused on caregiver burden in parents of children with CP. Paediatric research focusing on caregiver burden has mainly investigated the problems in connection to asthma, diabetes, cancer and mucoviscoidosis. ${ }^{21}$ In the present study in accordance with the adopted categories of burden, the level of subjective burden was found at a moderate level (2.59), similar to burden experienced by those caring for patients who had a stroke (2.08). ${ }^{14}$ In the assessments of caregiver burden, in addition to the diversity and specificity of clinical problems related to the primary parents'

Table 12 Regression model for predicting Caregiver Burden Scale-environment

\begin{tabular}{|c|c|c|c|}
\hline \multirow{3}{*}{$\begin{array}{l}\text { Independent } \\
\text { variables }\end{array}$} & \multicolumn{3}{|l|}{ Environment } \\
\hline & $\mathrm{R}^{2}=8.9 \%$ & $F=9.2$ & $p=0.0002$ \\
\hline & B (95\% Cl) & $\beta$ & $P$ value \\
\hline $\begin{array}{l}\text { Age of children } \\
\text { (years) }\end{array}$ & $\begin{array}{l}0.030(0.006 \text { to } \\
0.053)\end{array}$ & 0.175 & 0.0136 \\
\hline Barthel Index & $\begin{array}{l}-0.031(-0.047 \text { to } \\
-0.015)\end{array}$ & -0.264 & 0.0002 \\
\hline
\end{tabular}


Table 13 Regression model for predicting Caregiver Burden Scale-overall burden

\begin{tabular}{|c|c|c|c|}
\hline \multirow{3}{*}{$\begin{array}{l}\text { Independent } \\
\text { variables }\end{array}$} & \multicolumn{3}{|l|}{ Overall burden } \\
\hline & $R^{2}=13.4 \%$ & $F=9.6$ & $\mathrm{p}<0.0001$ \\
\hline & B (95\% Cl) & $\boldsymbol{\beta}$ & $P$ value \\
\hline $\begin{array}{l}\text { Age of children } \\
\text { (years) }\end{array}$ & $\begin{array}{l}0.020(0.002 \text { to } \\
0.038)\end{array}$ & 0.154 & 0.0313 \\
\hline Barthel Index & $\begin{array}{l}-0.024(-0.036 \\
\text { to }-0.011)\end{array}$ & -0.264 & 0.0002 \\
\hline $\begin{array}{l}\text { Health status } \\
\text { (worse vs better) }\end{array}$ & $\begin{array}{l}0.230 \text { (0.076 to } \\
0.384)\end{array}$ & 0.208 & 0.0037 \\
\hline
\end{tabular}

burden, ${ }^{6-13} 17-20$ the age of the person requiring assistance is of great importance. In the case of CP, the child's age corresponds to the duration of the disorder. The present study shows positive linear association of the child's age with all the measures of burden, with an exception of emotional involvement. With the child's age (duration of the disorder) there is an increase in the parents' general strain and social isolation. In view of the clinical specificity of CP syndrome, the result suggesting increase in general strain seems logical. The increase in social isolation with the child's age may be interpreted as a consequence of long-term commitment to care-related duties, which over time leads to decline in vitality, contributing to the caregiver's health problems, suffering, suicidal thoughts and desperation. ${ }^{30}$ Consequently, those primarily responsible for care-dependent people in the related literature are referred to as 'hidden patients', themselves in need of support and professional help, even though they determine the care provided to others. ${ }^{31} 32$ According to the present findings the burden of care increases with lower functional efficiency of the child (BI) and with the parents' poorer health status. On the other hand, the level of disappointment decreases with the parents' age, which possibly may be explained by the fact that they become increasingly used to the daily hardships. Other authors also reported that caregivers' poor health status was associated with greater burden of care reflected by higher indicators of stress and disappointment. ${ }^{33}$ Duration of a disorder also was a significant predictor of caregiver burden, directly affecting the caregivers' quality of life. ${ }^{34}$ Long-term effects of predictors may lead to more severe symptoms of depression which are more noticeable in continuing assessment of people's behaviours. ${ }^{35}$ Analysis of burden conducted by Haugstvedt $e t$ al showed that the highest burden of care was closely associated with the use of medical care, physical and mental problems, impaired family relations and social limitations of the child. ${ }^{36}$ As it was pointed out in the Results section, the highest level of burden was identified in the categories of emotional involvement and general strain linked with occurrence of physical and emotional difficulties induced by care-related activities and problems. No references to emotional burden of care were found in results reported by other researchers.
It seems that efforts to effectively manage health problems of one's own child and to meet care-related standards may certainly be associated with emotional burden of care. According to other authors, the highest level of burden was linked with general strain $^{32}$ and social isolation. ${ }^{33}$ Comparison of caregiver burden related to various disease entities showed that CP is linked with the highest general strain, social isolation and disappointment. ${ }^{37}$ Higher general strain, social isolation and disappointment are associated with such perceived effects of the child's condition as reduced regular income from work, and limited opportunity for leisure. ${ }^{32}$ Families with lower socioeconomic status experience greater financial burden, even if a specific medical condition entails lower expenditures. ${ }^{38}$ The level of burden was found to correlate with the child's age, and the parents' occupational status and education. ${ }^{32}$ The present study does not show an association of the parents' occupational status and education with caregiver burden, yet it seems logical that competence in handling care-related problems is a significant predictor of burden. Education gives broader opportunities in searching for knowledge, and acquiring skills, which in turn determines efficient management of childcare problems. ${ }^{39}$ Through education caregivers learn to prevent and recognise stressors, and to solve care-related problems. By using education as a support system for parents of children with CP, it may be possible to significantly reduce the level of their burden. The current findings show that greater caregiver burden appears to contribute to higher level of anxiety and depression. The measures of burden related to intensity of anxiety symptoms include disappointment and environment connected with the child's physical functioning in and out of home. On the other hand, depression symptoms are associated with emotional involvement and overall burden. It was observed that subjects who were more involved emotionally were less likely to present severe depression symptoms. In studies by Cheshire et al and Unsal-Delialioglu et al depression was found to be an important prognostic factor for caregiver burden, reflected by a significant positive linear relationship. ${ }^{4041}$ The current findings are in line with observations reported by other researchers, saying that the level of emotional problems in a parent is not only a determinant of the burden but also constitutes a visible consequence of care-related duties. ${ }^{42}$ The present study shows that a higher score in GMFCS corresponds to greater burden of care, particularly in the dimensions of environment and emotional involvement. The current findings are consistent with those reported by Camargos et al who assessed burden of caring for children with CP, and applied Burden Interview scale for this purpose. The study showed that the variables of poor socioeconomic status of the family, and the child's motor capacities produced the most negative effects as regards caregiver burden. ${ }^{43} \mathrm{~A}$ literature review conducted for the current study failed to identify results related to predictors of burden in caring for children with CP which would, to a high degree, 
explain variability in the measures of burden. In a study by Campbell et al a search for causes of burden in caring for individuals with dementia ended with finding a regression model comprising seven factors, and explaining $80 \%$ of the variance in caregiver burden. Most of those factors, that is, quality of patient-caregiver relationship, experience of adverse life events, caregivers' level of neuroticism, and level of caregiver confidence were related to dependent variables of the caregiver's personality. ${ }^{44}$ It is difficult to apply these findings to parents taking care of children with CP, because of the differences in the specific clinical aspects of these types of care, and the involvement in effective management of health problems to ensure balanced development of one's own child. ${ }^{1}$ In my opinion the present findings cannot provide definitive answers related to the causes of a given state; they can only present options for further assessments in longitudinal studies.

\section{CONCLUSIONS}

Caregiver burden is at a moderate level. The highest level of burden was identified in the categories of emotional involvement and general strain. There is a positive linear relation between the measures of burden and intensity of anxiety or depression symptoms. The subjects who are more emotionally involved present less severe depression symptoms. With the child's age (duration of the disorder) there is an increase in the parents' general strain and social isolation. Forward stepwise regression analysis showed multiple effects of the determinants in caregiver burden. The key predictors of caregiver burden include the child's age, motor capacity and functional status, and the parent's health status and age. The current findings may be helpful for service providers in designing a comprehensive, family-oriented support programme taking into account factors related to burden of care. Such interventions may contribute to the integrity of the families and promote parental caregivers' well-being, and consequently lead to improved quality of care provided to children with CP. Given the variety of factors affecting caregiver burden, further research should investigate and compare burden of care in different societies with diverse characteristics.

Acknowledgements The author appreciates support of all the persons cooperating in the process of collecting data, and is also thankful to all parents who participated in this study. The author is also grateful to Marek Sobolewski, PhD, for his advice concerning the statistics.

Contributors Study concept and design, funding acquisition, data acquisition, statistical analysis, analysis and interpretation of data, supervision: manuscript drafting: BG.

Funding The author has not declared a specific grant for this research from any funding agency in the public, commercial or not-for-profit sectors.

Competing interests None declared.

Patient consent for publication Not required.

Ethics approval All subjects gave their informed consent for inclusion before they participated in the study. The study was approved by the Bioethical Commission at the University of Rzeszów (KB/3/06/2013). The study was conducted in line with the Declaration of Helsinki.
Provenance and peer review Not commissioned; externally peer reviewed.

Data availability statement № data are available. All data relevant to the study are included in the article. For deidentified participant data access to author's ORCID: http://orcid.org/0000-0001-5807-0595.

Open access This is an open access article distributed in accordance with the Creative Commons Attribution Non Commercial (CC BY-NC 4.0) license, which permits others to distribute, remix, adapt, build upon this work non-commercially, and license their derivative works on different terms, provided the original work is properly cited, appropriate credit is given, any changes made indicated, and the use is non-commercial. See: http://creativecommons.org/licenses/by-nc/4.0/.

\section{ORCID iD}

Barbara Gugała http://orcid.org/0000-0001-5807-0595

\section{REFERENCES}

1 Basińska M, Wędzińska M. Fatigue with everyday life and satisfaction with life of parents of children with cerebral palsy. In: Wudarski A, ed. In search of the quality of life: an interdisciplinary study: a jubilee book dedicated to Romuald Derbis. Częstochowa, Akademia im: Jana Długosza, 2014: 245-58.

2 Rethlefsen SA, Ryan DD, Kay RM. Classification systems in cerebral palsy. Orthop Clin North Am 2010;41:457-67.

3 Oskoui M, Coutinho F, Dykeman J, et al. An update on the prevalence of cerebral palsy: a systematic review and meta-analysis. Dev Med Child Neurol 2013;55:509-19.

4 Mclntyre S, Taitz D, Keogh J, et al. A systematic review of risk factors for cerebral palsy in children born at term in developed countries. Dev Med Child Neurol 2013;55:499-508.

5 Bottcher L. Children with spastic cerebral palsy, their cognitive functioning, and social participation: a review. Child Neuropsychol 2010;16:209-28.

6 Mausbach BT, Chattillion EA, Roepke SK, et al. A comparison of psychosocial outcomes in elderly Alzheimer caregivers and noncaregivers. Am J Geriatr Psychiatry 2013;21:5-13.

7 Abreu W, Rodrigues T, Sequeira C, et al. The experience of psychological distress in family caregivers of people with dementia: a cross-sectional study. Perspect Psychiatr Care 2018;54:317-23.

8 Joling KJ, van Marwijk HWJ, Veldhuijzen AE, et al. The two-year incidence of depression and anxiety disorders in spousal caregivers of persons with dementia: who is at the greatest risk? Am J Geriatr Psychiatry 2015;23:293-303.

9 Liu S, Li C, Shi Z, et al. Caregiver burden and prevalence of depression, anxiety and sleep disturbances in Alzheimer's disease caregivers in China. J Clin Nurs 2017;26:1291-300.

10 Torres Á, Blanco V, Vázquez FL, et al. Prevalence of major depressive episodes in non-professional caregivers. Psychiatry Res 2015;226:333-9.

11 Roth DL, Perkins M, Wadley VG, et al. Family caregiving and emotional strain: associations with psychological health in a national sample of community-dwelling middle-aged and older adults. Qual Life Res 2009;18:679-88.

12 Gugała B, Penar-Zadarko B, Pięciak-Kotlarz D, et al. Assessment of anxiety and depression in Polish primary parental caregivers of children with cerebral palsy compared to a control group, as well as identification of selected predictors. Int J Environ Res Public Health 2019;16:4173.

13 Grootenhuis MA, Bronner MB. Paediatric illness! family matters. Acta Paediatr 2009;98:940-1.

14 Jaracz K, Grabowska-Fudala B, Górna K, et al. Burden in caregivers of long-term stroke survivors: prevalence and determinants at 6 months and 5 years after stroke. Patient Educ Couns 2015;98:1011-6.

15 Pearlin LI, Mullan JT, Semple SJ, et al. Caregiving and the stress process: an overview of concepts and their measures. Gerontologist 1990;30:583-94.

16 Bastawrous M. Caregiver burden - a critical discussion. Int J Nurs Stud 2013;50:431-41.

17 Oliveira D, Sousa L, Orrell M. Improving health-promoting self-care in family carers of people with dementia: a review of interventions. Clin Interv Aging 2019;14:515-23.

18 Mausbach BT, Chattillion EA, Roepke SK, et al. A comparison of psychosocial outcomes in elderly Alzheimer caregivers and noncaregivers. Am J Geriatr Psychiatry 2013;21:5-13.

19 Abreu W, Rodrigues T, Sequeira C, et al. The experience of psychological distress in family caregivers of people with dementia: a cross-sectional study. Perspect Psychiatr Care 2018;54:317-23. 
20 Zhu W, Jiang Y. A meta-analytic study of predictors for informal caregiver burden in patients with stroke. J Stroke Cerebrovasc Dis 2018;27:3636-46.

21 Cousino MK, Hazen RA. Parenting stress among caregivers of children with chronic illness: a systematic review. J Pediatr Psychol 2013;38:809-28.

22 Geng H-M, Chuang D-M, Yang F, et al. Prevalence and determinants of depression in caregivers of cancer patients: a systematic review and meta-analysis. Medicine 2018;97:e11863.

23 Watson B, Tatangelo G, McCabe M. Depression and anxiety among partner and offspring carers of people with dementia: a systematic review. Gerontologist 2019;59:5.

24 Simón MA, Bueno AM, Otero P, et al. Caregiver burden and sleep quality in dependent people's family caregivers. J Clin Med 2019;8:1072.

25 World Medical Association. World Medical association declaration of Helsinki: ethical principles for medical research involving human subjects. JAMA 2013;310:2191.

26 Grabowska -Fudala B, Jaracz K, Górna K. Obciążenie opiekunów chorych PO udarze mózgu- wyniki wstępne oceny prospektywnej. Nowiny Lekarskie 2012;81:3-9.

27 Martin CR, Tweed AE, Metcalfe MS. A psychometric evaluation of the hospital anxiety and depression scale in patients diagnosed with end-stage renal disease. Br J Clin Psychol 2004;43:51-64.

28 Wade DT, Hewer RL. Functional abilities after stroke: measurement, natural history and prognosis. J Neurol Neurosurg Psychiatry 1987;50:177-82.

29 Palisano RJ, Rosenbaum P, Bartlett D, et al. Content validity of the expanded and revised gross motor function classification system. Dev Med Child Neurol 2008;50:744-50.

30 Pouraboli B, Abedi H, Abbaszadeh A. Silent screams: experiences of caregiver suffering by parents of children with thalassemia: a qualitative study. J Qual Res Health Sci 2014;3:281-91.

31 Sawatzky JE, Fowler-Kerry S. Impact of caregiving: listening to the voice of informal caregivers. $J$ Psychiatr Ment Health Nurs 2003;10:277-86.

32 Kobos E, Imiela J. Factors affecting the level of burden of caregivers of children with type 1 diabetes. Appl Nurs Res 2015;28:142-9.
33 Rubira EA, Marcon SR, Belasco AGS. Burden and quality of life of caregivers of children and adolescents with chemotherapy treatment for cancer. Acta Paul Enferm 2012;25:567-73.

34 Nagaraju K, Wilson J. Burden and stress perceived by mothers having autistic children. IJRSMS 2013;1:53-7.

35 Ones K, Yilmaz E, Cetinkaya B, et al. Assessment of the quality of life of mothers of children with cerebral palsy (primary caregivers). Neurorehabil Neural Repair 2005;19:232-7.

36 Haugstvedt A, Wentzel-Larsen T, Rokne B, et al. Perceived family burden and emotional distress: similarities and differences between mothers and fathers of children with type 1 diabetes in a populationbased study. Pediatr Diabetes 2011;12:107-14.

37 Raina P, O'Donnell M, Rosenbaum P, et al. The health and wellbeing of caregivers of children with cerebral palsy. Pediatrics 2005;115:e626-36.

38 Lindley LC, Mark BA. Children with special health care needs: impact of health care expenditures on family financial burden. $J$ Child Fam Stud 2010;19:79-89.

39 Medway M, Tong A, Craig JC, et al. Parental perspectives on the financial impact of caring for a child with CKD. Am J Kidney Dis 2015;65:384-93.

40 Unsal-Delialioglu S, Kaya K, Ozel S, et al. Depression in mothers of children with cerebral palsy and related factors in turkey: a controlled study. Int J Rehabil Res 2009;32:199-204.

41 Cheshire A, Barlow JH, Powell LA. The psychosocial well-being of parents of children with cerebral palsy: a comparison study. Disabil Rehabil 2010;32:1673-7.

42 Marrón E, Boixadós M, Redolar-Ripoll D. Burden on caregivers of children with cerebral palsy: predictors and related factors. Universitas Psychologica 2013;12:767-77.

43 Camargos ACR, Lacerda TTB, Viana SO, et al. Assessment of the caregiver burden of children with cerebral palsy using the burden interview scale. Rev Bras Saúde Matern Infantil 2009;9:31-7.

44 Campbell P, Wright J, Oyebode J, et al. Determinants of burden in those who care for someone with dementia. Int J Geriatr Psychiatry 2008;23:1078-85. 